\title{
RELATIONSHIP BETWEEN LEARNING BEHAVIORS AND SOCIAL PRESENCE IN ONLINE COLLABORATIVE LEARNING
}

\author{
Yufan $\mathrm{Xu}^{1}$, Yuta Taniguchi ${ }^{2}$, Yoshiko Goda ${ }^{3}$, Atsushi Shimada ${ }^{2}$ and Masanori Yamada ${ }^{1}$ \\ ${ }^{I}$ Graduate School of Human-Environment Studies, Kyushu University \\ 744, Motooka, Nishi-ku, Fukuoka 819-0395, Japan \\ ${ }^{2}$ Faculty of Information Science and Electrical Engineering, Kyushu University \\ 744, Motooka, Nishi-ku, Fukuoka 819-0395, Japan \\ ${ }^{3}$ Research Center for Instructional Systems, Kumamoto University \\ 2-39-1, Kurokami, Chuo-ku, Kumamoto, 8600862 Japan
}

\begin{abstract}
This study examined the factors of learning behaviors in digital-learning-material reader that predict university students' productive participation identified by social presence indicators in online collaborative learning. Data were collected from 76 Frist-year university students, including learning behaviors in digital learning-material readers, and frequency of each social presence indicator classified by coding discussion scripts with automated text classification. The results of the stepwise multiple regression analysis revealed that the learning behavior of drawing red markers, highlighting important content predicts social presence. Furthermore, the study's findings showed that different learning behaviors predict different social presence indicators, which are related to metacognition and critical thinking.
\end{abstract}

\section{KEYWORDS}

Online Learning Participation, Computer-Supported Collaborative Learning, Learning Analytics, Learning Behaviors, Social Presence, Community of Inquiry

\section{INTRODUCTION}

Online learning has become a popular learning experience based on a pedagogical approach-Computer-Supported Collaborative Learning (CSCL) (e.g., Barria et al., 2012). Online learning participation is related to learning satisfaction and learning performance (Cobb, 2009; Hrastinski, 2009). However, there are variations in online learning participation due to an apparent lack of information on learning behaviors and monitoring from other learners (Swan and Hiltz, 2006). According to previous studies, sharing learners' information by the developing visualization system enhances online learning participation (Barria et al., 2014; Jin, 2017). However, according to a study, identifying productive participation by discussion using quantitative variables, such as frequency of logging in and length of discussion scripts, is not sufficient (Richards, 2011). In addition, individual learning behaviors with respect to preparation of learning materials affect participation (Vonderwell and Zachariah, 2005), and are considered for designing a visualization system. However, factors of learning behaviors that have an influence on participation have not been clarified. Moreover, an effective online learning environment underlying appropriate CSCL design must be established (Stahl and Koschamann, 2006). In line with this, the Learning Analytics (LA) approach is applied to collect and analyze learning log data from Learning Management Systems (LMS). In this study, we investigate the relationship between learning behaviors and productive participation using LA. 


\section{LITERATURE REVIEW}

\subsection{Online Learning with Computer-Supported Collaborative Learning}

Online learning is a widespread learning method uses advanced Information and Communication Technology and CSCL - a field of research and activities wherein people learn together by utilizing computers (Stahl and Koschamann, 2006; Xing et al., 2015; Yamada et al., 2015). With the benefits of CSCL, online discussion aims at hosting knowledge building exercises based on social interaction, including information exchange and information integration. Such discussions can be conducted at the time and place of the learners' choosing (Razmerita and Brun, 2010). In addition, learning logs data from LMSs can be collected and analyzed to facilitate CSCL. For example, Yin et al. (2017) examined the sequence of learning behaviors in "BookRoll" (Ogata et al, 2015; Ogata et al, 2017) — a digital-learning-material reader - and they found one sequence showing that deleting markers follows adding markers. Accordingly, Yin et al's (2017) study concluded that a teacher's affordance, including pointing out important content, should be provided by using "BookRoll." Teacher's affordance helps learners prepare their discussions in CSCL. Furthermore, CSCL with Community of Inquiry (CoI) provides an online learning environment where learners build knowledge socially and become critical thinkers (e.g., Garrison, 2011).

\subsection{Online Learning Participation with Community of Inquiry}

As mentioned above, online learning participation affects learning satisfaction and learning performance (Cobb, 2009; Hrastinski, 2009). However, online learning participation is inherently lower than that in classrooms or face-to-face (Swan et al., 2006). Online learning environment helps learners who fail to monitor themselves or other learners' progress hide themselves from others easily. There are several studies to enhance collaborative learning and participation in active discussions. Visualization of concept mapping in CSCL affected active collaborative learning from the view of social presence and learning (Yamada, 2010; Yamada et al, 2016). Barria et al. (2014) argued that providing learning information can enhance participation by visualization systems, and they provided learners with a Social Network Analysis (SNA) result to improve participation in online learning. In addition, Jin (2017) developed a visualization system by encouraging participation identified by the frequency of logging in, and the frequency or length of discussion scripts and proved that the system can enhance participation in online learning.

However, these studies focused on group level information, such as discussion scripts, neglecting individual level information related to preparing for online learning, such as learning behaviors including reading learning materials, highlighting important contents, etc. In addition, Richards (2011) indicated the necessity for qualitative variables to identify productive participation, such as opening threads, advising, agreement with others' ideas, etc. According to this, quantitative variables that emphasize these visualization systems (Barria et al., 2014; Jin, 2017) are insufficient. In the current study, we need to identify productive participation by qualitative variables.

The CoI framework is a powerful model for creating social consciousness and knowledge building exercises in online education in the absence of face-to-face interaction (Garrison et al., 1999; Yamada and Kitamura, 2011), and it has three components or presences: social presence, cognitive presence, and teaching presence.

Social presence is the ability of participants to project their personal characteristics into the community in order to present themselves to other participants as "real people" (Garrison et al., 1999). Cognitive presence indicates constructing and confirming the meaning-thought discourse (Garrison et al., 2001). Teacher presence is identified as "design and organization, facilitating discourse, and direct instruction" to support social and cognitive presence. In previous studies, social presence was identified as productive participation in online learning (Cobb, 2009; Garrision, 2011; Zou, 2020), and it was divided into individual, inter-individual, and granular social presence to show the senders' and receivers' cycle in CSCL design (Yamada and Kitamura, 2011). Through this analysis, learners' social presence, based on CSCL design, can be enhanced, and it can help them focus more on discussions (Gada and Yamada, 2013). 
In this study, we identify productive participation based on social presence indicators, which is re-examined by Shea et al. (2010). Thus, we analyze the relationship between learning behaviors and participation by LA, in terms of the CSCL design.

\subsection{Learning Analytics and Learning Behaviors}

LA is a promising method for collecting and analyzing learners' learning behaviors and processes. Yin et al. (2015) suggested that data from a learning log can be useful in predicting a learner's learning style and performance. For example, learning behaviors, such as "NEXT," "PREV," "MEMO," and "MARKER" in a "BookRoll" can be recorded to prove which of these behaviors can predict learning performance and test scores using a machine learning algorithm. The result showed that "MARKER" can predict learning performance (Nian et al., 2019). In addition, some learning behaviors related to attendance or absence, submission of reports, and quiz scores can predict the learning score (Okubo et al., 2016). Learners who participated in out-of-class learning activities on "BookRoll" tended to gain higher scores than ones who did not (Shimada et al., 2015). Moreover, by analyzing the frequency and area marked in the "BookRoll," Xu et al. (2020) found that the area marked was more strongly correlated with learning performance than the frequency of using markers. The result indicates that a teacher should give hints to highlight important content in an appropriate area when using digital-learning-material readers like "BookRoll." These studies suggested that LA can examine the relationship between learning log data to design and facilitate a learning environment.

As mentioned above, learning behaviors affected productive participation identified by social presence in CSCL. By using learning analytics, we can identify factors of learning behaviors which affect participation and are associated with social presence. Regarding CSCL and visualization design, it is also significant to find out the indicators of social presence that can be predicted by learning behaviors. In this study, we set two research questions (RQs).

RQ1: Which factors of learning behaviors affect social presence?

RQ2: Which indicator of social presence can be predicted by learning behaviors?

\section{METHODOLOGY}

\subsection{Participants and Class}

In this study, an instructor teaching a seven-week online educational technology course in K university's 2020 spring semester was recruited to participate. The participants were 76 Frist-year university students from different faculties.

The time of each lecture was 90 minutes per week. The participants possessed fundamental skills, such as computer use, conversation, and self-learning. In the first lecture, the instructor introduced the purpose of the course and how to use "BookRoll" to prepare and review learning materials, which the instructor uploaded. For each lecture, the participants were asked to access the "TEAMS" conference software to take the online class. In each of the $2^{\text {nd }}-7^{\text {th }}$ lectures, the discussion about practical educational questions was conducted in groups using a chat system called "CQCHAT" (Yamada et al., 2016). Participants were randomly assigned into groups of four or five. After each lecture, participants were asked to submit a mini-paper about what they had learned and were unfamiliar with. One week after the last lecture, the participants prepared the final reports.

\subsection{Data Collection}

Data were collected from two aspects-learning behavior logs and discussion scripts. The first data collection was based on learning behavior logs, recorded from "BookRoll" where the participants read digital learning materials using some reading functions. In this study, 10 types of 32,626 learning behavior logs were collected as follows: Turning to the next page (NEXT); Turing to the previous page (PREV); adding red (ADD_MK_RED) or yellow markers (ADD_MK_YEL); deleting red (DEL_MR_RED) or yellow markers 
(DEL_MR_YEL); adding (ADD_BK) or deleting a bookmark (DEL_BK); adding (ADD_MO) or deleting (DEL_MO) a memo.

The second data collection was based on discussion scripts. We collected 4,198 discussion scripts from the "CQCHAT" chat system during the $2^{\text {nd }}-7^{\text {th }}$ lectures. In the current study, such scripts were encoded into 3 categories of social presence including 18 indicators by using an automated text classification system (Yamada et al., 2015; Taniguchi et al., 2019) as follows: "affective" includes expressions of emotions (EMOTIONS), use of humor (HUMOR), self-disclosure (SELF-DISCLOSURE), use of unconventional expressions (PARALANGUAGE) and expressing value (VALUE); "open communication" includes continuing a thread (THREAD), quoting from other's messages (QUOTING), referring explicitly to other's messages (REFERRING), asking questions (QUESTION), complimenting or expressing appreciation (APPRECIATION), expressing agreement (AGREEMENT), expressing disagreement (DISAGREEMENT), and personal advice (ADVICE); "group cohesion" includes addressing or referring to participants by name (VOCATIVE), addressing the group as group (INCLUSIVE), serving a purely social function (PHATIC), social sharing (SOCIAL-SHARING), and course reflection (REFLECTION).

\section{RESULT AND DISCUSSION}

\subsection{Descriptive Data of Learning Behaviors and Social Presence Indicators}

The dataset was collected from two aspects-learning behavior logs and discussion scripts coded by social presence indicators. Table 1 shows the descriptive data (Average, Standard Deviations, Minimum and Maximum) of 10 types of learning behaviors, 6 social presence indicators (excluding 12 social indicators because of their empty values) and a sum of social presence scores called SOCIAL PRESENCE.

Table 1. Descriptive data of learning behaviors and social presence indicators during the course

\begin{tabular}{lllll}
\hline Variable & Average & SD & Minimum & Maximum \\
\hline NEXT & 298.87 & 272.10 & 21 & 1696 \\
PREV & 88.33 & 87.46 & 3 & 462 \\
ADD_MO & 0.64 & 1.47 & 0 & 8 \\
DEL_MO & 0.05 & 0.22 & 0 & 1 \\
ADD_BK & 0.07 & 0.30 & 0 & 2 \\
DEL_BK & 0.05 & 0.28 & 0 & 2 \\
ADD_MR_RED & 27.74 & 33.56 & 0 & 147 \\
ADD_MR_YEL & 9.49 & 26.96 & 0 & 156 \\
DEL_MR_RED & 3.00 & 8.45 & 0 & 55 \\
DEL_MR_YEL & 1.05 & 4.59 & 0 & 28 \\
PARALANGUAGE & 2.74 & 3.78 & 0 & 26 \\
VALUE & 7.34 & 5.87 & 0 & 4 \\
REFERENCE & 0.29 & 0.78 & 0 & 8 \\
QUESTION & 1.32 & 2.28 & 0 & 10 \\
AGREEMENT & 1.05 & 1.83 & 0 & 8 \\
PHATICS & 2.71 & 1.92 & 0 & 44 \\
SOCIAL PRESENCE & 15.45 & 12.24 & 0 & 26 \\
\hline
\end{tabular}

\subsection{Effects of Learning Behaviors on Productive Participation}

To answer RQ1, a stepwise multiple regression analysis was conducted to clarify which of the learning behaviors predict the productive participation identified by the 6 social presence indicators. First, we set the sum of social presence scores as the dependent variable; the independent variables ADD_MR_RED $(\beta=.304$, $\mathrm{p}=.007)$ accounted for $8.0 \%$ of the variance of social presence: $\mathrm{F}(1,74)=7.560, \mathrm{p}=.007$. The results are shown in Table 2. The regression results indicate that ADD_MR_RED can predict social presence identified by coding discussion scripts. As a learning strategy, the learning behavior of ADD_MR_RED means highlighting important content, which is related to one basic aspect of metacognition — knowledge monitoring 
ability (Van Horne et al., 2016). If learners cannot differentiate between what they know and do not know, they can hardly participate in metacognitive activities like discussions (Tobias and Everson, 2002). Additionally, in Wyre's (2007) study, metacognition influences critical thinking, which is associated with the discussion. For example, learners who are aware of important contents can focus on topics and assess others' speech during discussion.

Table 2. Results of the regression analysis predicting social presence with learning behaviors during the course

\begin{tabular}{lllll}
\hline Variable & B & SE B & $\beta$ & $\mathrm{t}$ \\
\hline ADD_MR_RED & .111 & .040 & .304 & $2.750^{* *}$ \\
\hline & & & $\mathrm{R} 2=.093$, Adjusted R2 $=.080, * * \mathrm{p}<0.01, * \mathrm{p}<.05$
\end{tabular}

To answer RQ2, we set 6 social presence indicators as dependent variables and conducted stepwise multiple regression analysis, respectively. Regarding dependent variables PARALANGUAGE, VALUE, and QUESTION, independent variables DEL_MR_RED $(\beta=.259, \mathrm{p}=.024 ; \beta=.236, \mathrm{p}=.040 ; \beta=.304$, $\mathrm{p}=.008$ ) accounted for $5.4 \%$ of the variance of PARALANGUAGE: $\mathrm{F}(1,74)=5.312, \mathrm{p}=.024 ; 4.3 \%$ of the variance of VALUE: $\mathrm{F}(1,74)=4.377, \mathrm{p}=.040 ; 8.0 \%$ of the variance of QUESTION: $\mathrm{F}(1,74)=7.511$, $\mathrm{p}=.008$, respectively (tables 3, 4, and 5). DEL_MR_RED, which means deleting important contents highlighted by learners, is also related to knowledge monitoring ability, as mentioned previously (Van Horne et al., 2016). According to the coding scheme for social presence, PARALANGUAGE indicates unconventional expression of emotions, such as repetitious punctuation and emoticons (Shea et al., 2010). In Hoy's (2018) study, metacognition is associated with emotions. For example, during a discussion, when a learner is empathetic in their speech, he tends to use some unconventional expressions of emotion due to the lack of facial expressions in a text-based environment. VALUE is defined by expressing personal values, beliefs, and attitudes (Shea et al., 2010); it is associated with DEL_MR_RED, one of the metacognitive strategies. Tyshchuk et al. (2018) demonstrated that VALUE which is one of elements of human behaviors was represented by perceived behavioral control. The findings suggested learners' beliefs are largely congruent with their behaviors; however, the mechanism between learners' beliefs and behaviors is not apparent (Kamiya, 2018). In addition, learners' attitudes and beliefs are important concepts in understanding an action while teaching others (Richardson, 1996). That is, the attitudes and beliefs affect the way of teaching other group members, such as preparation for the focus area. The results show that QUESTION, which means asking a question, is associated with DEL_MR_RED. Learners who highlighted the important contents generally deleted these before discussion. However, during a discussion, others' speech about these contents induce questions on reasons that these contents are important. In addition, asking a question-not consistent with one's thought—is associated with critical thinking (Sharan, 2010).

Table 3. Results of the regression analysis predicting the social presence indicator PARALANGUAGE with learning behaviors during the course

\begin{tabular}{lllll}
\hline Variable & B & SE B & $\beta$ & $\mathrm{t}$ \\
\hline DEL_MR_RED & .116 & .050 & .259 & $2.305^{*}$ \\
\hline & & $\mathrm{R} 2=.067$, Adjusted R2 $=.054,{ }^{* *} \mathrm{p}<.01,{ }^{*} \mathrm{p}<.05$
\end{tabular}

Regarding the dependent variable REFERENCE, the independent variables DEL_MR_YEL $(\beta=.364$, $\mathrm{p}=.001)$ and DEL_MO $(\beta=.222, \mathrm{p}=.040)$ accounted for $15.7 \%$ of the variance of REFERENCE: $\mathrm{F}(2,73)=7.965, \mathrm{p}=.001$. DEL_MR_YEL and DEL_MO imply that they had comprehended what they did not previously know and REFERENCE indicates direct references to contents of others' post (Shea et al., 2010). Moreover, markers can help learners decide what they should focus on (Yue et al, 2015). During the discussion, other learners discuss topics which have been comprehended by one learner; this can make the learner interested in the topic and propose his ideas.

With respect to the dependent variable AGREEMENT, the independent variable DEL_MR_YEL $(\beta=.355, \mathrm{p}=.002)$ accounted for $12.6 \%$ of the variance of $\operatorname{AGREEMENT:~} F(1,74)=10.644, \mathrm{p}=.002$. In a previous study, markers helped learners retrieve their knowledge (Yue et al, 2015). For example, learners can think of approaches or means through which the unfamiliar content can be comprehended. During the discussion, this content was proposed by learners because those who know about it had agreed to discussing it. 
Table 4. Results of the regression analysis predicting the social presence indicator VALUE with learning behaviors during the course

\begin{tabular}{lllll}
\hline Variable & B & SE B & $\beta$ & $\mathrm{t}$ \\
\hline DEL_MR_RED & .164 & .078 & .236 & $2.092^{*}$ \\
\hline & & $\mathrm{R} 2=.056$, Adjusted R2 $=.043,{ }^{* *} \mathrm{p}<.01,{ }^{*} \mathrm{p}<.05$
\end{tabular}

Table 5. Results of the regression analysis predicting the social presence indicator QUESTION with learning behaviors during the course

\begin{tabular}{lllll}
\hline Variable & B & SE B & $\beta$ & $\mathrm{t}$ \\
\hline DEL_MR_RED & .082 & .030 & .304 & $2.741 * *$ \\
\hline & & $\mathrm{R} 2=.092$, Adjusted R2 $=.080,{ }^{* *} \mathrm{p}<.01,{ }^{*} \mathrm{p}<.05$
\end{tabular}

Table 6. Results of the regression analysis predicting the social presence indicator REFERENCE with learning behaviors during the course

\begin{tabular}{lllll}
\hline Variable & B & SE B & B & t \\
\hline DEL_MR_YEL & .062 & .002 & .364 & $3.432 * *$ \\
DEL_MO & .770 & .368 & .222 & $2.092^{*}$ \\
\hline & & & & R2 $=.179$, Adjusted R2 $=.157, * * p<.01, * p<.05$
\end{tabular}

Table 7. Results of the regression analysis predicting the social presence indicator AGREEMENT with learning behaviors during the course

\begin{tabular}{lllll}
\hline Variable & B & SE B & $\beta$ & $\mathrm{t}$ \\
\hline DEL_MR_YEL & .141 & .043 & .355 & $3.262^{* *}$ \\
\hline & & $\mathrm{R} 2=.126$, Adjusted R2 $=.114, * * \mathrm{p}<.01,{ }^{*} \mathrm{p}<.05$
\end{tabular}

In terms of PHATIC as a dependent variable, the independent variable NEXT $(\beta=.397, \mathrm{p}=.000)$ accounted for $15.8 \%$ of the variance of PHATIC: $F(1,74)=13.844, p=.000$. According to Shea et al.'s (2010) study, PHATIC is identified by greeting. NEXT means turning to the next page while preparing for discussion, which can motivate the learners to participate in the discussion and greet other learners. Conversely, according to Yin et al. (2015), NEXT may possibly mean that learners have just read their learning materials. However, in this study, we cannot prove whether the learners just learned their materials. Hence, in the future, we will analyze the correlation between learning behavior patterns and social presence.

Table 8. Results of the regression analysis predicting the social presence indicator PHATIC with learning behaviors during the course

\begin{tabular}{lllll}
\hline Variable & B & SE B & $\beta$ & $\mathrm{t}$ \\
\hline NEXT & .003 & .001 & .397 & $3.721 * *$ \\
\hline & & $\mathrm{R} 2=.158$, Adjusted R2 $=.146,{ }^{* *} \mathrm{p}<.01,{ }^{*} \mathrm{p}<.05$
\end{tabular}

\section{CONCLUSION AND FUTURE WORK}

In this paper, we analyzed the factors of learning behaviors in "BookRoll," predicting productive participation in discussion which are identified by social presence indicators in an online learning environment. The results show that highlighting important content, which help learners decide on the focus area, can promote participation in a discussion. In addition, deleting important or unfamiliar content related to a basic aspect of metacognitive learning — knowledge monitoring (Tobias and Everson, 2002) — promotes discussion scripts expressing emotion by using paralanguage; such discussion scripts are based on learners' beliefs. The learner behavior of deleting markers can also affect discussion scripts based on agreement to others' ideas, questions, and references to the content of other learners' posts. However, whether learning behaviors of turning to the next page is positive and why such behaviors are related to PHATIC needs further analysis. 
In our future work, we will use these findings to improve our visualization system which aims to promote productive participation in online discussions. The visualization system's contents related to learning behaviors, like frequency of markers, memos, and bookmarks in "BookRoll," should be reconsidered. In line with Yamada et al. (2015) 's research, we will investigate which functions of system affect perceived and expressive social presence. Moreover, according to the advantages of highlighting learning contents (Yue et al, 2015), we can visualize some detailed information regarding markers, such as highlighting those contents which were deleted by learners.

\section{ACKNOWLEDGEMENT}

This study was supported by Japan Society for the Promotion of Science (JSPS) [grant number JP18K18657, JP19H01716, JP20H01727] and JST AIP [grant number JPMJCR19U1].

\section{REFERENCES}

Barría, J., Scheihing, E., \& Parra, D. (2014). Visualizing student participation in a collaborative learning environment. In F. Cena, A. S. da Silva, \& C. Trattner (Eds.), Hypertext HT (Doctoral Consortium/Late-breaking Results/Workshops), CEUR Workshop Proceedings (Vol. 1210). Santiago, Chile: CEUR-WS.org.

Cobb, S. C. (2009). Social presence and online learning: A Current view from a research perspective. Journal of Interactive Online Learning, 8(3), 241-254.

Garrison, D. R., Anderson, T., \& Archer, W. (1999). Critical inquiry in a text-based environment: Computer conferencing in higher education. The Internet and Higher Education, 2(2-3), 87-105.

Garrison, D. R., Anderson, T., \& Archer, W. (2001). Critical thinking, cognitive presence, and computer conferencing in distance education. American Journal of Distance Education, 15(1), 7-23.

Garrison, D. R. (2011). E-learning in the 21st century: A framework for research and practice. In Taylor \& Francis, Routledge.

Goda, Y., \& Yamada, M. (2013). Application of CoI to design CSCL for EFL online asynchronous discussion. In Akyol, Z. \& Garrison D. R. (eds.), Educational communities of inquiry: Theoretical framework, research and practice (pp. 295-316). IGI Global, Hershey.

Hoy, R. C. (2018). Emotion and metacognitive monitoring: The role of Emotion in the development of learning beliefs. Individual, Family, and Community Education ETDs, New Mexico.

Hrastinski, S. (2009). A theory of online learning as online participation. Computers and Education, 52(1), 0-82.

Jin, S. H. (2017). Using visualization to motivate student participation in collaborative online learning environments. Educational Technology \& Society, 20(2), 51-62.

Kamiya, N. (2018). Teacher and Student Beliefs. The TESOL Encyclopedia of English Language Teaching, 1-6.

Nian, M. W., Lee, Y. H., \& Wu, J. Y. (2019). Using machine learning to explore the associations among e-reader operations and their predictive validity of learning performance. International Conference on Learning Analytics \& Knowledge (LAK19) (pp. 1-6).

Ogata, H., Yin, C., Oi, M., Okubo, F., Shimada, A., Kojima, K., \& Yamada, M. (2015, January). E-Book-based learning analytics in university education. International Conference on Computer in Education (ICCE 2015) (pp. 401-406).

Ogata, H., Taniguchi, Y., Suehiro, D., Shimada, A., Oi, M., Okubo, F., ... \& Kojima, K. (2017). M2B system: A digital learning platform for traditional classrooms in university. Practitioner Track Proceedings, 155-162.

Okubo, F., Hirokawa, S., Terai, M., Shimada, A., Kentaro, K., Yamada, M., \& Ogata, H. (2016, January). Learning activity features of high performance students. In CEUR Workshop Proceedings (Vol. 1601, pp. 28-33). CEUR-WS.

Razmerita, L., \& Brun, A. (2010, December). Assigning Students in Groups: Self-formed Groups versus Automatically-formed Groups. In 7ème Colloque Technologies de l'Information et de la Communication pour l'Enseignement-TICE.

Richards, G. (2011). Measuring engagement: Learning analytics in online learning. electronic Kazan, 2011.

Richardson, V. (1996). The role of attitudes and beliefs in learning to teach. Handbook of research on teacher education, 2(102-119).

Saltz, J. S., Hiltz, S. R., \& Turoff, M. (2004, November). Student social graphs: visualizing a student's online social network. In Proceedings of the 2004 ACM conference on Computer supported cooperative work (pp. 596-599). 
Sharan, Y. (2010) Cooperative learning for academic and social gains: Valued pedagogy, problematic practice. European Journal of Education, 45(2), 300-13.

Shea, P., Hayes, S., Vickers, J., Gozza-Cohen, M., Uzuner, S., Mehta, R., ... \& Rangan, P. (2010). A re-examination of the community of inquiry framework: Social network and content analysis. The Internet and Higher Education, 13 (1-2), 10-21.

Shimada, A., Okubo, F., Yin, C., Kojima, K., Yamada, M., \& Ogata, H. (2015, July). Informal learning behavior analysis using action logs and slide features in e-textbooks. In 2015 IEEE 15th International Conference on Advanced Learning Technologies (pp. 116-117). IEEE.

Stahl, G., \& Koschmann, T. S. (2006). Computer-supported collaborative learning: An historical perspective. In R. K. Sawyer (ed.), Cambridge Handbook of the Learning Sciences, p. 409Á426. Cambridge University Press, Cambridge.

Swan, K., Shen, J., \& Hiltz, S. R. (2006). Assessment and collaboration in online learning. Journal of Asynchronous Learning Networks, 10(1), 45-62.

Taniguchi, Y., Konomi, S., \& Goda, Y. (2019, January). Examining language-agnostic methods of automatic coding in the community of inquiry framework. In 16th International Conference on Cognition and Exploratory Learning in Digital Age, CELDA 2019 (pp. 19-26). IADIS Press.

Tobias, S., \& Everson, H. T. (2002). Knowing What You Know and What You Don't: Further Research on Metacognitive Knowledge Monitoring. Research Report No. 2002-3. College Entrance Examination Board.

Tyshchuk, Y., \& Wallace, W. A. (2018). Modeling human behavior on social media in response to significant events. IEEE Transactions on Computational Social Systems, 5(2), 444-457.

Van Horne, S., Russell, J. E., \& Schuh, K. L. (2016). The adoption of mark-up tools in an interactive e-textbook reader. Educational Technology Research and Development, 64(3), 407-433.

Vonderwell, S., \& Zachariah, S. (2005). Factors that influence participation in online learning. Journal of Research on Technology in Education, 38(2), 213-230.

Wyre, S. H. (2007). Critical thinking, metacognition, and epistemological beliefs (Doctoral dissertation, University of Phoenix).

Xing, W., Wadholm, R., Petakovic, E., \& Goggins, S. (2015). Group learning assessment: Developing a theory-informed analytics. Journal of Educational Technology \& Society, 18(2), 110-128

Xu,Y., Geng, X., Chen, L., Hamada, S., Taniguchi, Y., Ogata, H., Shimada, A., and Yamada, M. (2020). Can the Area marked in eBook Readers Specify Learning Performance? Companion Proceedings 10th International Conference on Learning Analytics \& Knowledge (LAK20), pp.638-648.

Yamada, M. (2010). Development and Evaluation of CSCL Based on Social Presence. In E-Learn: World Conference on E-Learning in Corporate, Government, Healthcare, and Higher Education (pp. 2304-2309). Association for the Advancement of Computing in Education (AACE).

Yamada, M., \& Kitamura, S. (2011). The role of social presence in interactive learning with social software. In Social media tools and platforms in learning environments (pp. 325-335). Springer, Berlin, Heidelberg.

Yamada, M., Goda, Y., Matsukawa, H., Hata, K., \& Yasunami, S. (2015). A computer-supported collaborative learning design for quality interaction. IEEE MultiMedia, 23(1), 48-59.

Yamada, M., Kaneko, K. and Goda, Y. (2016). Social Presence Visualizer: Development of the Collaboration Facilitation Module on CSCL. In T. Yoshino, G-D. Chen, G. Zurita, T. Yuizono, T. Inoue, \& N. Baloian (Eds.) Collaboration Technologies and Social Computing - Lecture Note of Communications in Computer and Information Science, 647, 174-189.

Yin, C., Okubo, F., Shimada, A., Oi, M., Hirokawa, S., Yamada, M., Kojima, K., \& Ogata, H. (2015). Analyzing the features of learning behaviors of students using e-books. In Proceedings of the International Conference on Computers in Education (pp. 617-626).

Yin, C., Uosaki, N., Chu, H. C., Hwang, G. J., Liu, G. Z., Hwang, J. J., Hatono, I., Kumamoto, E., \& Tabata, Y. (2017, January). Learning behavioral pattern analysis based on students' logs in reading digital books. Proceedings of the 25th International Conference on Computers in Education (pp. 549-557).

Yue, C. L., Storm, B. C., Kornell, N., \& Bjork, E. L. (2015). Highlighting and its relation to distributed study and students' metacognitive beliefs. Educational Psychology Review, 27(1), 69-78.

Zou, W., Hu, X., Pan, Z., Li, C., Cai, Y., \& Liu, M. (2020). Exploring the relationship between social presence and learners' prestige in MOOC discussion forums using automated content analysis and social network analysis. Computers in Human Behavior, 106582. 